\title{
A METHOD FOR THE ASSESSING OF RELIABILITY CHARACTERISTICS RELEVANT TO AN ASSUMED POSITION-FIXING ACCURACY IN NAVIGATIONAL POSITIONING SYSTEMS
}

\author{
Cezary Specht, Prof. \\ Gdynia Maritime University, Poland \\ Jacek Rudnicki, PhD \\ Gdańsk University of Technology, Poland
}

\begin{abstract}
This paper presents a method which makes it possible to determine reliability characteristics of navigational positioning systems, relevant to an assumed value of permissible error in position fixing. The method allows to calculate: availability , reliability as well as operation continuity of position fixing system for an assumed, determined on the basis of formal requirements - both worldwide and national, position-fixing accuracy. The proposed mathematical model allows to satisfy, by any navigational positioning system, not only requirements as to position-fixing accuracy of a given navigational application (for air, sea or land traffic) but also the remaining characteristics associated with technical serviceability of a system.

Essence of the method in question consists in the working-out of recorded empirical position-fixing data as well as the making use of multi-state Markov processes (appropriate to a maximum error value permissible for various navigational applications ) as a result of which reliability characteristics based on real data would be determined. About usefulness of a given navigational positioning system for its possible application would decide a vector of variables (both dealing with position and reliability) which satisfies / or does not satisfy/ formal navigational requirements for a given application.
\end{abstract}

Keywords: reliability, accuracy, availability, navigational positioning systems

\section{FORMAL REQUIREMENTS FOR NAVIGATIONAL POSITIONING SYSTEMS}

The working-out radio-navigational plans, resolutions and recommendations, by international navigation- orientated institutions, is conductive for forming legal regulations aimed at ensuring a balanced and harmonized development of national, regional and worldwide radio-navigational systems. Their range of application deals with position-fixing requirements for all kinds of navigation $[1,2,3,5,6]$ or is limited to one of its kinds: maritime [4], airborne [9] or even to a single application, e.g. hydrographical one [8]. Their scope covers:

- description of current functioning state of radio-navigational systems as well as time services available in a given country and neighbouring regions, together with a short technical description and services,

- plans concerning extending, development, closing or modernization of radio-navigational systems with taking into account research on their development carried out domestically and abroad,

- determination of national requirements for all types, phases and kinds of navigation as well as definition of institutional responsibility for radio-navigational and positioning service . The requirements constitute a set of operational 
characteristics of the systems together with minimum numerical values assigned to them.

It should be stressed that only a few countries have undertaken to describe the matters in question in the form of uniform national official regulations : USA [6], Sweden [5], UK [3], covering all the forms of navigation. However the remaining ones introduce such requirements in practice in the form of national documents of a lower rank. Out of all legal solutions, the approach of USA should be especially distinguished, where Federal Radio-navigational Plan, very important legal document concerning the requirements for process of navigation, and which describes also the process of development and evolution of systems, is regularly published.

In the above mentioned documents the requirements for navigation process concern all kinds of navigation ( maritime, aircraft and land ) with taking into account their phases. An example of the requirements for maritime navigation process during harbour entrance and approach phase is presented in Tab. 1.

As results from the above mentioned normalizing documents, in order to safely perform process of navigation ( maritime, aircraft or land ) one should have at his disposal a positioning system which meets all the above specified navigational characteristics. Hence a question of a fundamental character arises : which way to assess whether a given positioning system is capable of meeting the above specified requirements. An additional difficulty in the assessing is continuous improving the positioning systems, which results in changes ( elevating) navigational characteristics of majority of contemporary positioning systems. Let's consider for instance GPS system which, for a dozen or so of last years, has permanently increased positionfixing accuracy [14]. The accuracy with the use of GPS system ( in horizontal plane) was equal to : in 1993 - $100 \mathrm{~m}$ (2drms) $[10,11]$, in $2001-13 \mathrm{~m}$ (2drms) [12] , and in 2008 - as much only as $9 \mathrm{~m}$ (2drms) [13]. As a result of this fact, number of applications of the system increases and increases. For instance, as early as in 1993 the system in question did not meet position-fixing requirements for car navigation due to its too low accuracy $(100 \mathrm{~m})$, but already in 2001 it could be used satisfactorily in the above mentioned kind of navigational application $(10 \mathrm{~m})$. The below attached figure presents a synthesis of the requirements for transport applications (maritime, aircraft and land) in function of position-fixing accuracy ( $\mathrm{x}$-axis) as well as availability ( $\mathrm{y}$-axis), based on an analysis of the data contained in the publications $[2,3,5$, 6]. The transport applications are presented in the form of icons. The grey- marked applications are those in which GPS system met their requirements in the years $1994 \div 2001$. Blue colour shows the possibility of GPS in the years $2001 \div 2008$, and green colour relates to the years from 2008 till now.

The analysis shown in Fig. 1 proves that number of applications of GPS system has grown year in, year out and that it results from values, currently attained by the system, of particular characteristics (accuracy, availability, reliability, continuity and credibility) which are published by U.S. Defence Department in the official form only every a few years. The last standard was published in 2008 [13].

In this paper is proposed a method which makes it possible to assess possibility of using a positioning system in an arbitrary navigational application from the point of view of requirements dealing with its accuracy, availability, reliability and continuity. It consists in working out empirical positionfixing data achieved from an operating system as well as using multi-state Markov processes ( relevant to maximum value of permissible position -fixing error in different navigational applications); as a result of this, reliability characteristics based on real data would be determined. About usefulness of a given navigational positioning system for its possible application would decide a vector of variables (both dealing with position and reliability) which satisfies ( or does not satisfy) formal navigational requirements for a given application.

Tab. 1. Maritime User Requirements/Benefits for Purposes of System Planning and Development - Harbour Entrance and Approach Phase [6]

\begin{tabular}{|c|c|c|c|c|c|c|}
\hline \multirow[b]{2}{*}{ REQUIREMENTS } & \multicolumn{6}{|c|}{ MEASURES OF MINIMUM PERFORMANCE CRITERIA TO MEET REQUIREMENTS } \\
\hline & $\begin{array}{c}\text { ACCURACY } \\
\text { (meters, } 2 \text { drms) }\end{array}$ & AVAILABILITY & CONTINUITY & INTEGRITY & $\begin{array}{l}\text { TIME TO } \\
\text { ALERT }\end{array}$ & COVERAGE \\
\hline $\begin{array}{l}\text { Safety of Navigation (Large } \\
\text { Ships \& Tows) }\end{array}$ & $8-20^{* \star *}$ & $99.7 \%$ & $\star \star \star$ & TBD & TBD & $\begin{array}{l}\text { U.S. harbor entrance } \\
\text { and approach }\end{array}$ \\
\hline $\begin{array}{l}\text { Safety of Navigation } \\
\text { (Smaller Ships) }\end{array}$ & $8-20$ & $99.9 \%$ & $\approx *$ & TBD & TBD & $\begin{array}{l}\text { U.S. harbor entrance } \\
\text { and approach }\end{array}$ \\
\hline Resource Exploration & $1-5^{*}$ & $99 \%$ & ** & TBD & TBD & $\begin{array}{l}\text { U.S. harbor entrance } \\
\text { and approach }\end{array}$ \\
\hline $\begin{array}{c}\text { Engineering and } \\
\text { Construction Vessels } \\
\text { Harbor Phase }\end{array}$ & $0.1^{* \star * *}-5$ & $99 \%$ & $\star * *$ & TBD & TBD & $\begin{array}{l}\text { Entrance channel \& } \\
\text { jetties, etc. }\end{array}$ \\
\hline
\end{tabular}

\begin{tabular}{|c|c|c|c|c|c|c|}
\hline \multirow{2}{*}{ BENEFITS } & \multicolumn{5}{|c|}{ MEASURES OF MINIMUM PERFORMANCE CRITERIA TO MEET BENEFITS } \\
\cline { 2 - 7 } & $\begin{array}{c}\text { ACCURACY } \\
\text { (meters, 2drms) }\end{array}$ & AVAILABILITY & CONTINUITY & INTEGRITY & $\begin{array}{c}\text { TIME TO } \\
\text { ALERT }\end{array}$ & COVERAGE \\
\hline $\begin{array}{c}\text { Fishing, Recreational and } \\
\text { Other Small Vessels }\end{array}$ & $8-20$ & $99.7 \%$ & $*$ & TBD & TBD & $\begin{array}{c}\text { U.S. harbor entrance } \\
\text { and approach }\end{array}$ \\
\hline
\end{tabular}

* Based on stated user need.

*** Dependent upon mission time.

***** Varies from one harbor 


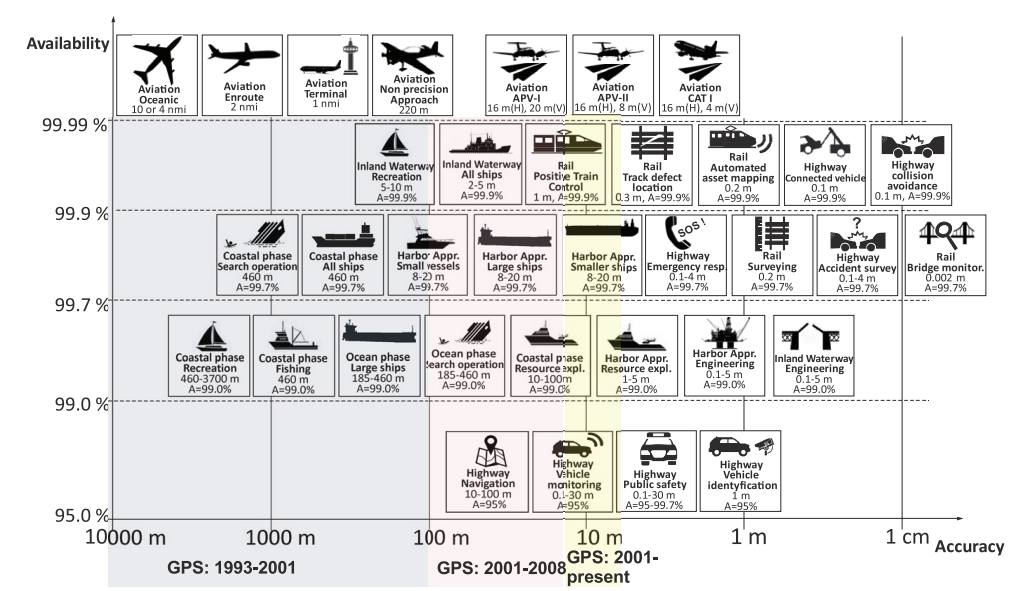

further the states, may be distinguished - from the point of view of its usability for realization of objective function (i.e. capability of securing a given navigational application)- depending on position fixing accuracy :

- $\quad$ Subset of states $\mathrm{S}_{1}$ - state which meets requirements of the application No. 1 for which value of the position-fixing accuracy is : $\varepsilon<1 \mathrm{~m}$

- $\quad$ Subset of states $\mathrm{S}_{2}$ - state which meets requirements of the application No. 2 and does not meet requirements of the application No.1 , and for which value of the position-fixing accuracy is in the range of $1 \mathrm{~m}<\varepsilon<2 \mathrm{~m}$
Fig. 1. Transport applications of GPS system during the years : $1993 \div 2008$, based on the requirements contained in $[1,2,3,5,6]$.

\section{MODEL OF POSITION-FIXING PROCESS EXECUTED BY NAVIGATIONAL SYSTEM AS A MARKOV PROCESS}

Let's consider the position-fixing process executed by positioning system, whose error in determination of coordinates in function of time is presented in Fig. 2. It may be assumed that it is the random process of reliability state changing $\{\mathrm{W}(\mathrm{t}): \mathrm{t} \geq 0\}$ constituted by the consecutive states $s_{i}$ - corresponding to accuracy requirements of the three navigational applications : Highway Vehicle Identification, Inland Waterway for all ships and Resource Exploration close to Harbour Approaches. The states belong to the set of the distinguished subsets of classes - states, $S=\left\{s_{i} ; i=1,2, \ldots, j\right\}$.

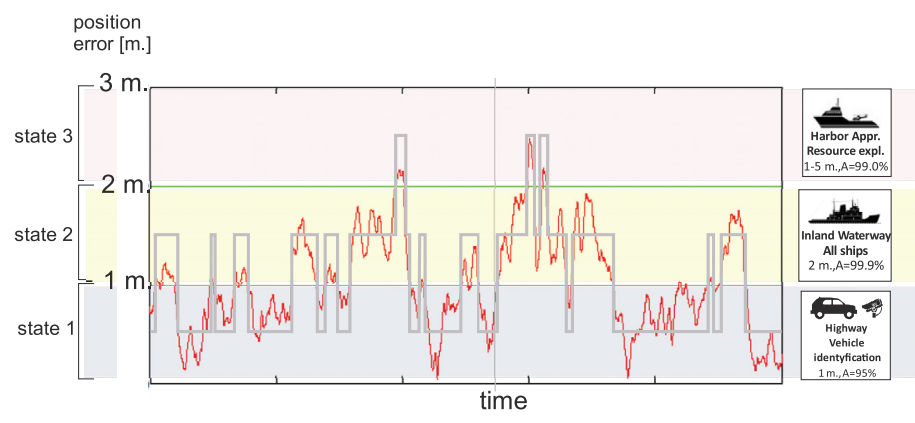

Fig. 2. Value of position-fixing error in function of time - as a multi-state random process ( of 3 states)

Acceptance of the following hypothesis to be right: „process of reliability state changing of positioning system is that whose state considered in an arbitrary instant $t_{n}\left(n=0,1, \ldots, m ; t_{0}<t_{1}<\right.$ $\ldots<t_{m}$ ) depends on the state directly preceding it and does not stochastically depend on the states which occurred earlier and their occurrence times" makes it possible to develop an adequate reliability model by using the theory of Markov ( or semiMarkov) processes [16]. Such model may be hence a Markov process of a discrete set of distinguished states and continuous time of their duration. In the light of the above discussed issues, in the set of possible reliability states of positioning system , S, the following subsets ( classes) of states, called
- Subset of states $S_{3}$ - state which meets requirements of the application No. 3 and does not meet requirements of the applications No.1 and 2 , and for which value of the position-fixing accuracy is in the range of $2 \mathrm{~m}<\varepsilon<3 \mathrm{~m}$.

Taking into account the above introduced division of the set $S$ one can present a graph of states - transitions of the process $\{\mathrm{W}(\mathrm{t}): \mathrm{t} \geq 0\}$, as follows [Fig. 3]:

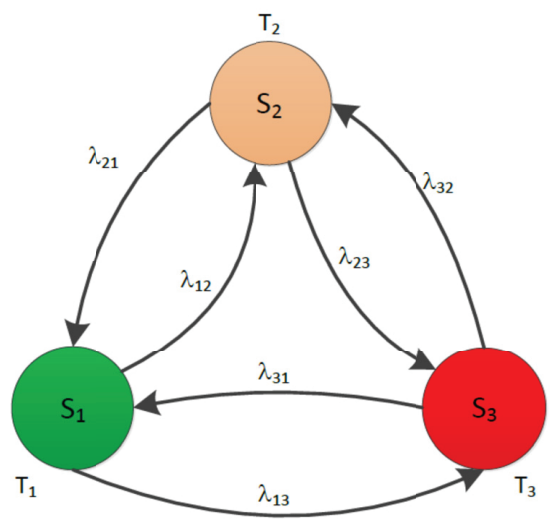

Fig. 3. Graph of states - transitions of the process $\{W(t): t \geq 0\}$ between the states : $s 1, s 2, s 3$; lik - intensity of transition from the state si under condition of transition of the process to the state $s k(i, k=1,2,3 i \neq k) ; T i$-random variable which describes time of staying in the state si irrespective of which state will be the next.

Initial distribution of the process $\{\mathrm{W}(\mathrm{t}): \mathrm{t} \geq 0\}$, under condition that in the initial instant $t=0$ the system is in the state $s_{1}$, can be described as follows:

$$
\mathrm{p}_{1}=\mathrm{P}\left\{\mathrm{W}(0)=\mathrm{s}_{1}\right\}=1, \mathrm{p}_{\mathrm{i}}=\mathrm{P}\left\{\mathrm{W}(0)=\mathrm{s}_{\mathrm{i}}\right\}=0 \text { for } \mathrm{i}=2,3 \text {. }
$$

To determine a distribution of a considered process it is first necessary to estimate values of the transition intensities $\lambda_{\mathrm{ik}}$ $(\mathrm{i}, \mathrm{k}=1,2,3 ; \mathrm{i} \neq \mathrm{k})$ of the following interpretation:

$$
\lambda_{i k}(t)=\lim _{\tau \rightarrow 0} \frac{\mathrm{P}\left(\mathrm{W}(\mathrm{t}+\tau)=\mathrm{s}_{\mathrm{k}} / W(t)=s_{i}\right)}{\tau} .
$$

In practice, a convenient and credible estimation of the 
magnitude may be the following which is determined on the basis of investigation of realizations of the random variables $T_{i k}[17]$ :

$$
\hat{\lambda}_{i k}=\frac{1}{E\left(T_{i k}\right)} \cong \frac{1}{\bar{T}_{i k}}, \quad(i, k=1,2,3 ; i \neq k)
$$

where:

$E\left(T_{i k}\right)$ - expected value of random variable which describes duration time of the state $s_{i}$ under condition that the state $\mathrm{s}$ will be the next;

$\bar{T}_{k k}$ - mean time of staying the system (engine) in the state $s_{i}$ under condition that the state $\mathrm{s}_{\mathrm{k}}$ will be the next .

Determination of probabilities of staying the system in particular states is possible by solving the set of Kolmogorov equations which can be generally presented in the following form , [18]:

$$
\frac{d P_{i}(t)}{d t}=-\left(\sum_{k} \lambda_{i k}\right) \cdot P_{i}(t)+\sum_{k}\left(\lambda_{k i} \cdot P_{k}(t)\right) \quad i \neq k .
$$

With taking into account the graph of changes of states of the process $\{\mathrm{W}(\mathrm{t}): \mathrm{t} \geq 0\}$ and its initial distribution for the considered case, the set may be expressed as follows :

$$
\left.\begin{array}{l}
\frac{d P_{1}(t)}{d t}=-\left(\lambda_{12}+\lambda_{13}\right) \cdot P_{1}(t)+\lambda_{21} \cdot P_{2}(t)+\lambda_{31} \cdot P_{3}(t) \\
\frac{d P_{2}(t)}{d t}=-\left(\lambda_{21}+\lambda_{23}\right) \cdot P_{2}(t)+\lambda_{12} \cdot P_{1}(t)+\lambda_{32} \cdot P_{3}(t) \\
\frac{d P_{3}(t)}{d t}=-\left(\lambda_{31}+\lambda_{32}\right) \cdot P_{3}(t)+\lambda_{13} \cdot P_{1}(t)+\lambda_{23} \cdot P_{2}(t)
\end{array}\right\}
$$

Among other important reliability characteristics possible to be determined with the use of the theory of Markov ( or semi-Markov) processes also the following may be numbered [16]:

- Limiting distribution of the process in question:

$$
\mathrm{p}_{\mathrm{j}}=\lim _{t \rightarrow \infty} \mathrm{P}\left\{\mathrm{W}(\mathrm{t})=\mathrm{s}_{\mathrm{j}}\right\}
$$

- Distribution of time of the first transition from the state $s_{i}$ to the distinguished subset of states $A$ : $\Phi_{i \mathrm{~A}}(\mathrm{t})$;

- Approximate distribution of total staying time of the process in the state $s_{k}$ under condition that the state $s_{i}$ will be initial one;

- Expected value of the duration time $\mathrm{T}_{\mathrm{i}}$ of the process state $s_{i}$, regardless of to which state its transition takes place in the instant $\tau_{\mathrm{n}+1}: \mathrm{E}\left(\mathrm{T}_{\mathrm{i}}\right)$;

- Variance of the time $\mathrm{T}_{\mathrm{i}}: \mathrm{D}^{2}\left(\mathrm{~T}_{\mathrm{i}}\right)$;

- Expected value of the duration time $\mathrm{T}_{\mathrm{i}}$ of the process state $s_{i}$ under condition that the state $s_{k}$ will be the next : $\mathrm{E}\left(\mathrm{T}_{\mathrm{ik}}\right)$;

- Mean number of "come-ins" ( per unit of time) of the process to the state $s_{j}$ under condition that the state $s_{i}$ will be initial one : $\lambda_{i k}(t)$.

\section{MODEL OF THE DETERMINING OF AVAILABILITY, RELIABILITY AND CONTINUITY OF MARKOV PROCESS STATES}

Let's define process of staying-in and failure of the state $S_{i}(t)$ in function of time as follows :

$$
S_{i}(t)=\left\{\begin{array}{cc}
1, & Z_{n}^{\prime \prime} \leq t<Z_{n+1}^{\prime} \\
0, & Z_{n+1}^{\prime} \leq t<Z_{n+1}^{\prime \prime}
\end{array} \quad \text { for } n=0,1, \ldots\right.
$$

where: the variables $Z_{n}^{\prime}$ are instants of failures ( changes from a given state to another ), and the instants $Z_{n}^{\prime \prime}$ are those of renewal of a considered state. Let $X_{1}, X_{2}, \ldots$ determine working time durations for a given state, and $Y_{1}, Y_{2}, \ldots$ correspond to instants of occurrence of failures (staying in other states). Let's assume that the random variables $X_{i}, Y_{i}$ for $i=1,2, \ldots$, are independent on each other and that duration times of work and failure of a structure have the same distribution. Let's assume that the cumulative distribution functions are continuous on the right, then :

$$
P\left(X_{i} \leq x\right)=F(x), P\left(Y_{i} \leq y\right)=G(y) i=1,2, \ldots,
$$

where :

$F(x)$ - cumulative distribution function of work duration times of a navigational structure,

$G(y)$ - cumulative distribution function of failure duration times of a navigational structure.

Moreover, let's assume that the variables have finite expected values and variances:

and

$$
E\left(X_{i}\right)=E(X), E\left(Y_{i}\right)=E(Y)
$$

$$
V\left(X_{i}\right)=\sigma_{1}^{2}, V\left(Y_{i}\right)=\sigma_{2}^{2} \text {. }
$$

Let's define availability of a given interval of position-fixing accuracy which corresponds to the state $S_{i}$, as a probability that a given position-fixing error is in the serviceability (working) state in an arbitrarily selected instant $t$, and that it may be expressed as follows :

$$
A_{S_{i}}(t)=P\left[S_{i}(t)=1\right]
$$

Then the formula for availability of a given position-fixing interval takes finally the form [15]:

$$
A_{S_{i}}(t)=1-F(t)+\int_{0}^{t}[1-F(t-x)] d H_{\Phi}(x),
$$

where :

$$
H_{\Phi}(x)=\sum_{n=1}^{\infty} \Phi_{i}(x)
$$

is a renewal function of the stream formed by renewal instants of the state $S_{i}$. The detailed derivation of the formula can be found in [15]. 
A functional form of $A_{S_{n}}$ is rather not very useful from the point of view of the estimating of availability of a given position-fixing accuracy interval, therefore in maritime navigation its limiting value is usually applied, that may be described as follows :

$$
\begin{aligned}
& A_{S_{i}}=\lim _{t \rightarrow \infty} P\left[\mathrm{~S}_{i}(t)=1\right]=\lim _{t \rightarrow \infty} A_{S_{i}}(t)= \\
& =\lim _{t \rightarrow \infty}\left\{1-F(t)+\int_{0}^{t}[1-F(t-x)] d H_{\Phi}(x)\right\} .
\end{aligned}
$$

After its transformations, one can achieve the following final form for the availability :

$$
A_{S_{i}}=\frac{E(X)}{E(X)+E(Y)} .
$$

The notion of reliability of a given position-fixing accuracy interval may be defined in an analogue way, namely, $R_{S_{i}}$ is probability of staying the position-fixing error in a given time interval (staying in the state) $[t, t+\tau)$, which has its final form as follows :

$$
R_{S_{i}}(t, \tau)=1-F(t+\tau)+\int_{0}^{t}[1-F(t+\tau-x)] d H_{\Phi}(x)
$$

and, its limiting value of the form:

$$
\lim _{t \rightarrow \infty} R_{S_{i}}(t, \tau)=\frac{1}{E(X)+E(Y)} \int_{\tau}^{\infty}[1-F(u)] d u,
$$

where : $x+\tau=u$.

The continuity of a given position-fixing accuracy interval and its limiting value take their respective forms as follows

$$
C_{S_{i}}(t, \tau)=\frac{1-F(t+\tau)+\int_{0}^{t}[1-F(t+\tau-x)] d H_{\Phi}(x)}{1-F(t)+\int_{0}^{t}[1-F(t-x)] d H_{\Phi}(x)}
$$

and

$$
\lim _{t \rightarrow \infty} C_{S_{i}}(t, \tau)=\frac{1}{E(X)} \int_{\tau}^{\infty}[1-F(u)] d u
$$

\section{RESULTS OF A NUMERICAL EXPERIMENT}

The developed model was applied to real position measurements taken by means of a typical maritime receiver of the differential system GPS ( DGPS) operating in the frequency band of $283.5 \div 325 \mathrm{KHz}$. The analysis covered 25 -day measurement session carried out with $1 \mathrm{~Hz}$ frequency. The total number of measurements was equal to 2210266 events of position fixing. The so large number of measurements made it possible to obtain a similar large number of states sufficient for conducting representative statistical reasoning. The real coordinates of the measurement point : $\mathrm{B}=5431.75524 \mathrm{~N}$, $\mathrm{L}=1833.57418 \mathrm{E}, \mathrm{H}=68.07 \mathrm{~m}$ were determined in WGS-84 system with employing the geodesic measurement techniques GNSS, with the accuracy of $1 \mathrm{~cm}$ (rms). Next, the geodesic coordinates measured by the measurement receiver DGPS were recalculated into the plane (Cartesian) coordinates by using Gauss-Kruger transformation. On the basis of the real coordinates as well as measurement results, errors of particular measurements (in meters) were determined for $2 \mathrm{D}$ coordinates - geographical latitude and longitude. Distribution of the coordinates versus real values is presented in Fig. 4.

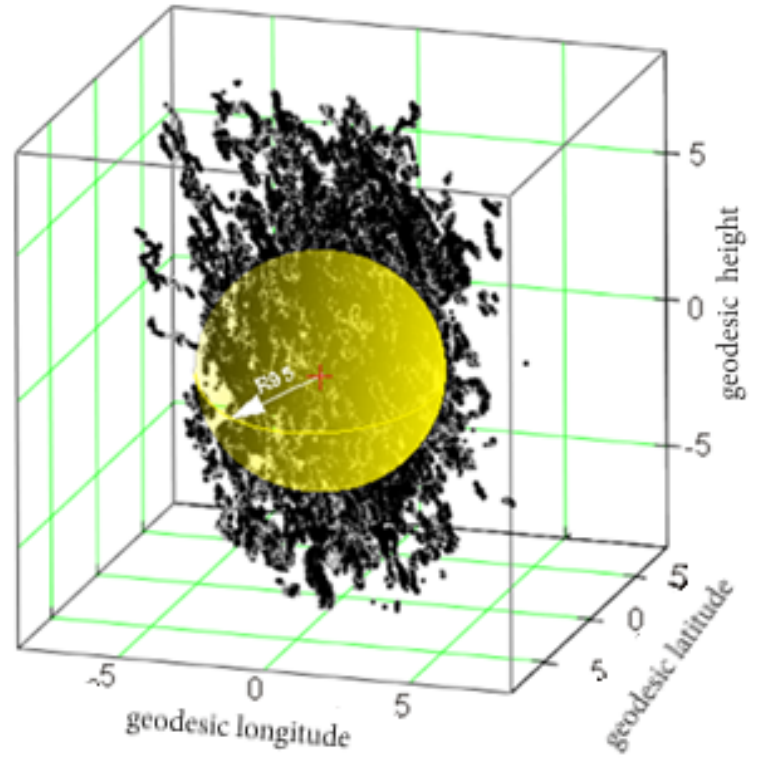

Fig. 4. Distribution of the positions measured by means of DGPS receiver versus real coordinates

The analysis was started from calculation of statistics of position-fixing errors with the use of typical navigational methods for estimating position accuracy, and consequently the following results were obtained : Latitude (rms) - $0.81 \mathrm{~m}$, Longitude (rms) - $0.62 \mathrm{~m}$, Altitude (rms) - $1.43 \mathrm{~m}$, drms (2D) $1.02 \mathrm{~m}, 2 \mathrm{drms}$ (2D) - $2.04 \mathrm{~m}, \mathrm{R} 35(2 \mathrm{D})-1.79 \mathrm{~m}, \mathrm{CEP}(3 \mathrm{D})-0.83$ m, R95 (3D)-3.04 m. For further analyses was used a set of $2 \mathrm{D}$ position-fixing errors, in which three example classes of process states were determined depending on $\varepsilon$-value :

- $s_{1}$ - the position-fixing error $\varepsilon \leq \varepsilon_{\text {dop }}=0,5117$,

- $\mathrm{s}_{2}$ - the position-fixing error

$$
\varepsilon_{\text {dop }}=0,5117<\varepsilon \leq \varepsilon_{\mathrm{kr}}=1,0234
$$

- $\mathrm{s}_{3}$ - the position-fixing error $\varepsilon>\varepsilon_{\mathrm{kr}}=1,0234$

As a result of the processing of data obtained on the basis of real measurements of position, were obtained realizations of the random variables $\mathrm{T}_{\mathrm{i}}, \mathrm{T}_{\mathrm{ik}}(\mathrm{i}, \mathrm{k}=1,2,3 ; \mathrm{i} \neq \mathrm{k})$ as well as the following numbers of process transitions from the state $\mathrm{s}_{\mathrm{i}}$ to the state $\mathrm{s}_{\mathrm{k}}$ :

- $\mathrm{n}_{12}=4870$;

- $\mathrm{n}_{13}=0$;

- $\mathrm{n}_{21}=4868$;

- $\mathrm{n}_{23}=4433$;

- $\mathrm{n}_{31}=2$;

- $\mathrm{n}_{32}=4431$; 
The achieved statistics made it possible to modify the graph of states and transitions (Fig. 3) as well as the set of equations (5) into the following form :

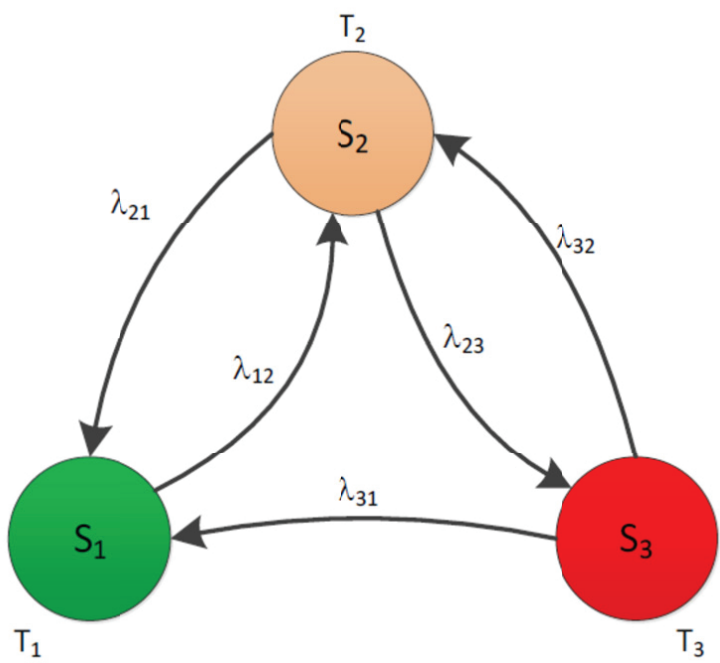

Fig. 5. The modified graph of states and transitions of the process $\{W(t): t \geq 0\}$.

$$
\left.\begin{array}{c}
\frac{d P_{1}(t)}{d t}=-\left(\lambda_{12}\right) \cdot P_{1}(t)+\lambda_{21} \cdot P_{2}(t)+\lambda_{31} \cdot P_{3}(t) \\
\frac{d P_{2}(t)}{d t}=-\left(\lambda_{21}+\lambda_{23}\right) \cdot P_{2}(t)+\lambda_{12} \cdot P_{1}(t)+\lambda_{32} \cdot P_{3}(t) \\
\frac{d P_{3}(t)}{d t}=-\left(\lambda_{31}+\lambda_{32}\right) \cdot P_{3}(t)+\lambda_{23} \cdot P_{2}(t)
\end{array}\right\}
$$

The empirical distributions of the random variables $\mathrm{T}_{\mathrm{i}}$ and $\mathrm{T}_{\mathrm{ik}}$ were used to verify statistical hypotheses as to their compliance with exponential distribution, and it was assumed that the values $\hat{\lambda}_{i k}$ determined according to the relations (3) may serve as the estimators of the parameters of the distributions, $\lambda_{i k}$. Their values are presented in Tab. 2 .

Tab. 2. Values of estimators of parameters of exponential distributions of the random variables $T_{i}$ and $T_{i k}$

\begin{tabular}{|c|c|c|c|}
\hline $\begin{array}{c}\text { Random } \\
\text { variable }\end{array}$ & $\begin{array}{c}\hat{\lambda} \\
{\left[\mathrm{s}^{-1}\right]}\end{array}$ & $\begin{array}{c}\text { Random } \\
\text { variable }\end{array}$ & $\begin{array}{c}\hat{\lambda} \\
{\left[\mathrm{s}^{-1}\right]}\end{array}$ \\
\hline $\mathrm{T}_{1}$ & 0,0095 & $\mathrm{~T}_{21}$ & 0,100 \\
\hline $\mathrm{T}_{2}$ & 0,100 & $\mathrm{~T}_{23}$ & 0,100 \\
\hline $\mathrm{T}_{3}$ & 0,0058 & $\mathrm{~T}_{32}$ & 0,0058 \\
\hline $\mathrm{T}_{12}$ & 0,0095 & $\mathrm{~T}_{31}$ & 0,0086 \\
\hline
\end{tabular}

The verification was performed with the use of the goodness -of- fit test $\chi^{2}$, and in order to select a true hypothesis $\mathrm{H}_{0}$, i.e. that for which is no basis to be rejected, the hypothesis selecting principle was assumed as follows :

- if $g_{0} \geq g_{\alpha}$ for $\alpha=0,05$ then $H_{0}$ should be rejected;

- if $g_{0}<g_{\alpha}$ for $\alpha=0,10$ then $H_{0}$ should be accepted;

- if $g_{0}<g_{\alpha}$ for $\alpha=0,05$ and for $\alpha=0,10 g_{0} \geq g_{\alpha}$ then goodness of $\mathrm{H}_{0}$ is dubious and the testing should be continued;

where :

- $\mathrm{g}_{0}$ - characteristic value of the test, determined on the basis of investigation results;

- $\mathrm{g}_{\alpha}$ - limiting value for the significance level $\alpha$, i.e. value of $\alpha$-order quantile of a selected statistics.

The applied test made it possible to state that there is no basis to reject successive hypotheses $\mathrm{H}_{0}$ on the conformity of the considered variables $\mathrm{T}_{\mathrm{i}}, \mathrm{T}_{\mathrm{ik}}$ with exponential distribution, therefore they were taken to be true. By making use of Laplace transform, initial distribution of the process $\{\mathrm{W}(\mathrm{t}): \mathrm{t} \geq 0\}$ and values $\hat{\lambda}_{i k}$ for solving the set of equations (18), the following set of linear equations was obtained in the domain of transformations :

$$
\left.\begin{array}{l}
s \cdot P_{1}^{*}(s)-1=-0,0095 \cdot P_{1}^{*}(s)+0,1 \cdot P_{2}^{*}(s)+0,0086 \cdot P_{3}^{*}(s) \\
s \cdot P_{2}^{*}(s)=0,0095 \cdot P_{1}^{*}(s)-0,2 \cdot P_{2}^{*}(s)+0,0058 \cdot P_{3}^{*}(s) \\
s \cdot P_{3}^{*}(s)=0,1 \cdot P_{2}^{*}(s)-0,0144 \cdot P_{3}^{*}(s)
\end{array}\right\}
$$

and after putting in order:

$$
\begin{aligned}
& (s+0,0095) \cdot P_{1}^{*}(s)-0,1 \cdot P_{2}^{*}(s)-0,0086 \cdot P_{3}^{*}(s)=1 \\
& \left.-0,0095 \cdot P_{1}^{*}(s)+(s+0,2) \cdot P_{2}^{*}(s)-0,0058 \cdot P_{3}^{*}(s)=0\right\} \\
& -0,1 \cdot P_{2}^{*}(s)+(s+0,0144) \cdot P_{3}^{*}(s)=0
\end{aligned}
$$

The solving of the presented set of equations and the executing of Laplace inverse transformation made it possible to find the distribution of the temporary process $\mathrm{p}_{\mathrm{j}}(\mathrm{t})=\mathrm{P}\{\mathrm{W}(\mathrm{t})$ $=s_{\mathrm{j}}$ \}. A graphical representation of the solution is given in Fig. 6.

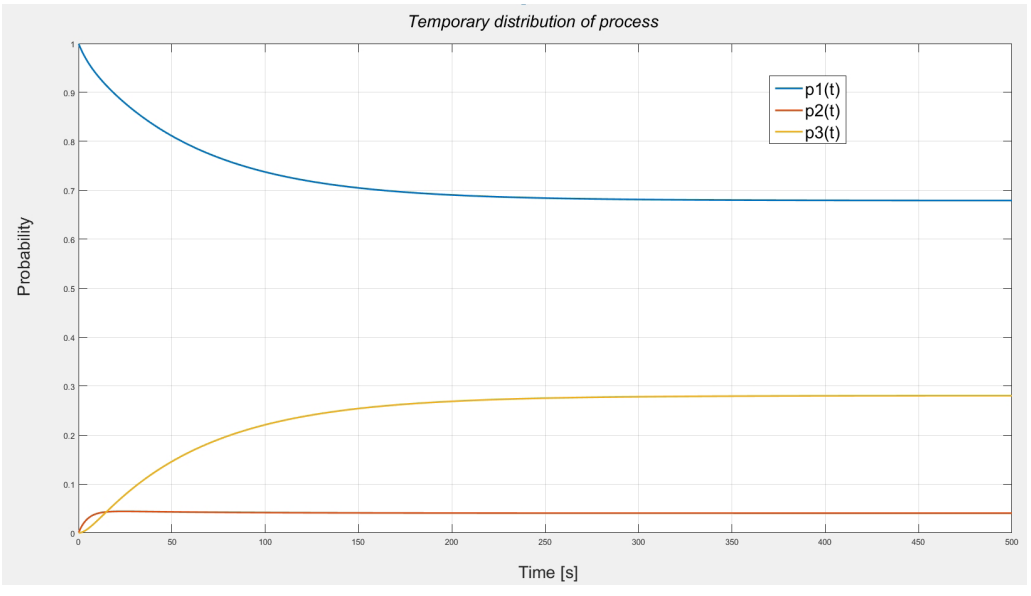

Fig. 6. Calculation results of the temporary distribution for the initial distribution $p_{1}=P\left\{W(0)=s_{1}\right\}=1, p_{i}=P\left\{W(0)=s_{i}\right\}=0$ for $i=2,3$;

Assuming the exponential distribution of operation and failure times, where:

$$
A_{\text {exp }}(t)=\frac{\mu}{\lambda+\mu}+\frac{\lambda}{\lambda+\mu} e^{-(\lambda+\mu) t} .
$$

with limiting value: 
where:

$$
A_{\text {exp }}=\frac{\frac{1}{\lambda}}{\frac{1}{\lambda}+\frac{1}{\mu}}=\frac{\mu}{\mu+\lambda},
$$

$\lambda, \mu$ - rates of failure and renewal

Positioning GNSS networking service reliability in the interval of time $[t, t+\tau)$ can be defined as the survival probability of a system where the position-fixing error reliability function can be presented as follows:

$$
R_{e x p}(t, \tau)=\left[\frac{\mu}{\lambda+\mu}+\frac{\lambda}{\lambda+\mu} e^{-(\lambda+\mu) t}\right] \cdot e^{-\lambda \tau},
$$

with limiting value:

$$
\lim _{t \rightarrow \infty} R_{e x p}(t, \tau)=\frac{\mu}{\lambda+\mu} \cdot e^{-\lambda \tau}
$$

And positioning service continuity could be represented by the formula:

$$
C_{\exp }(t, \tau)=e^{-\lambda \tau}
$$

with

$$
\lim _{t \rightarrow \infty} C_{\exp }(t, \tau)=e^{-\lambda \tau},
$$

Results of calculation are presented in the form of availability and reliability functions (Fig. 7).

\begin{tabular}{|c|c|c|c|}
\hline Parameters & 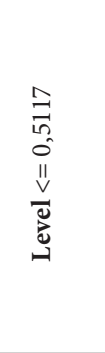 & 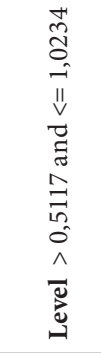 & 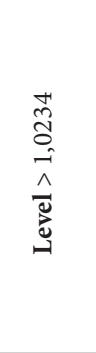 \\
\hline MTBF & $105.62 \mathrm{~s}$ & $100.10 \mathrm{~s}$ & $172.76 \mathrm{~s}$ \\
\hline $\begin{array}{c}\text { Availability } \\
\text { limiting value }\end{array}$ & $23.25 \%$ & $42.10 \%$ & $34.64 \%$ \\
\hline $\begin{array}{c}\text { Reliability } \\
\text { limiting value }\end{array}$ & $22.59 \%$ & $40.86 \%$ & $34.05 \%$ \\
\hline $\begin{array}{c}\text { Continuity } \\
\text { limiting value }\end{array}$ & $97.19 \%$ & $97.04 \%$ & $98.27 \%$ \\
\hline
\end{tabular}

Complete results of limiting values of availability, reliability and continuity are given in Tab. 4.
Tab. 4. Limiting values of availability, reliability and continuity for three selected states.

\section{CONCLUSIONS}

In this paper has been presented a method which makes it possible to determine reliability characteristics of navigational positioning systems relevant to a given value of permissible error in position fixing. Essence of the method consists in working-out the recorded empirical positioning data as well as using multi - state Markov processes (adequate to maximum value of position-fixing error permissible for various navigational applications) - and in that the reliability characteristics based on real data can be consequently determined. The proposed mathematical model allows to assess if it is possible to satisfy, by a given navigational positioning system, not only requirements for position-fixing accuracy of a given navigational application. Additionally a numerical

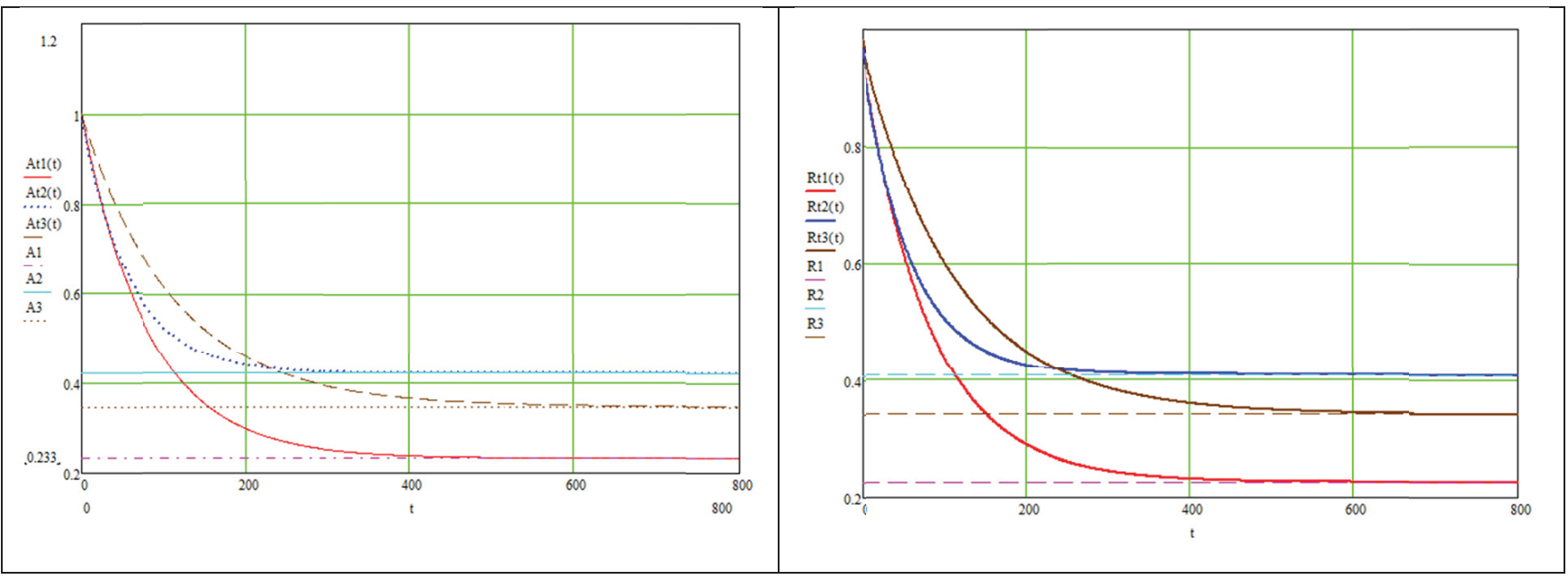

Fig. 7. Availability function (left) and reliability function (right) and their limiting values for three levels: $s_{1}, s_{2}, s_{3}$. 
example of application of the proposed method, based on recorded data of 2 million positions from EGNOS system, has been presented in this paper.

\section{BIBLIOGRAPHY}

1. ERNP 1996, European Radio-navigation Plan, First Draft For Working Group Review, Booz Allen \& Hamilton, Paris, 6 march, 1996.

2. ERNP 2004, European Radio Navigation Services, Development of the European Union Navigation Plan, Helios Technology Ltd, 25 October 2004.

3. GLA, 2007, General Lighthouse Authorities Radio Navigation Plan, The United Kingdom and Republic of Ireland, Delivering 2020 The Vision, January 2007.

4. WRNP 2009, International Association of Marine Aids to Navigation and Lighthouse Authorities, World Wide Radio Navigation Plan, , Edition 1, Saint Germain en Laye, France 2009.

5. SMA 2009, Swedish Radio Navigation Plan, Swedish Maritime Administration, Policy and Plans. 2009.

6. FRNP 2014, Federal Radio-navigation Plan, Department of Defence, Department of Homeland Security, Department of Transportation, Springfield, Virginia 2014.

7. IHO 1998, International Hydrographic Office, International Hydrographic Bureau, IHO standards for hydrographic surveys, special publication No. 44, 4th edition, 1998.

8. Dorst L.L. and Howlett C., 2006, Evolutions in the IHO standards for Hydrographic Surveys, S33, Proceedings of the International Hydrographic Conference'Evolutions in Hydrography',Hydro06, Antwerp, Belgium, 6 $\div 9$ November 2006.

9. ICAO 2006, International Civil Aviation Organization, Convention on International Civil Aviation, $9^{\text {th }}$ Edition, , 2006.

10. SPS 1993, United States of America Department of Defense, Global Positioning System Standard Positioning Service Signal Specification, November 1993.

11. SPS 1995, United States of America Department of Defense, Global Positioning System Standard Positioning Service Signal Specification, $2^{\text {nd }}$ Edition, June 1995.

12. SPS 2001, United States of America Department of Defense, Global Positioning System Standard Positioning Service Performance Standard, October 2001.

13. SPS 2008, United States of America Department of
Defense, Global Positioning System Standard Positioning Service Performance Standard, $4^{\text {th }}$ Edition, September 2008.

14. Specht C., Mania M., Skóra M., Specht M., 2015, Accuracy of the GPS Positioning System in the Context of Increasing the Number of Satellites in the Constellation, Polish Maritime Research No 22, Gdansk University of Technology, 2015, pp. $9 \div 14$

15. Specht C., 2003, Availability, Reliability and Continuity Model of Differential GPS Transmission, Annual of Navigation No. 5, Gdynia 2003.

16. Grabski F., 1982, Theory of semi-Markov processes of operation of technical objects (in Polish). Scientific Journal of Polish Naval Academy, No. 75A, Gdynia 1982.

17. Rudnicki J., 2015, Application Issues of the Semi-Markov Reliability Model, Polish Maritime Research, Vol. 22, Issue

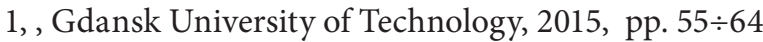

18. Modarres M., 1993, Reliability and Risk Analysis, Marcel Dekker Inc., New York 1993

\section{CONTACT WITH THE AUTHOR}

\author{
Cezary Specht \\ Gdynia Maritime University \\ Faculty of Navigation \\ 81-87 Morska St. \\ 81 - 225 Gdynia \\ Jacek Rudnicki \\ Gdańsk University of Technology \\ 11/12 Narutowicza St. \\ 80 - 233 Gdańsk \\ Poland
}

